УдК 621.382

\title{
ДВУХПОЛОСНЫЙ ФИЛЬТР НА ПРЯМОУГОЛЬНЫХ ДИЭЛЕКТРИЧЕСКИХ РЕЗОНАТОРАХ
}

\author{
ПОДГУРСКАЯ Т. В., ТРУБИН А. А.
}

Нацииональный технический университет Украины

«Киевский политехнический институт»,

Украина, Киев, 03056, пр-т Победь 37

\begin{abstract}
Аннотация. Предложен новый способ реализации двухполосных фильтров, выполненных на прямоугольных диэлектрических резонаторах. Для уменьшения размеров конструкции исследована возможность одновременной настройки двух полос пропускания на одной структуре связанных диэлектрических резонаторов с применением их собственных колебаний высших типов. Выполнено сравнение представленного аналитического решения с результатами моделирования методом конечных элементов. Численным методом рассчитаны и исследованы коэффициенты связи прямоугольных резонаторов для низшего дипольного $T E_{01 \delta}$ и высшего квадрупольного $T E_{02 \delta}$ магнитных типов колебаний в зависимости от параметров конструкции фильтра. Предлагаемый двухполосный фильтр на диэлектрических резонаторах может быть использован в базовых станциях, беспроводных точках доступа сетей связи
\end{abstract}

Ключевые слова: прямоугольный диэлектрический резонатор; диаграмма типов колебаний; электромагнитное поле; добротность; метод конечных элементов

\section{ВВЕДЕНИЕ}

С ростом предоставляемых беспроводных услуг возникает необходимость одновременного использования в системах связи нескольких полос частот [1], ключевым узлом которых является многополосный фильтр. Существует множество реализаций двухполосных фильтров в микрополосковом исполнении [2], а также с использованием combline-структур [3]. Однако использование указанных видов резонаторов в миллиметровом диапазоне затруднено из-за возрастающих потерь в металле. Требованиям минимальных потерь, реализуемых в полосе пропускания, наилучшим образом удовлетворяют фильтры на диэлектрических резонаторах (ДР) [4], которые характеризуются существенно большими значениями собст- венной добротности по сравнению с другими видами резонаторов.

На сегодняшний день существуют две основные конструкции двухполосных фильтров на ДР. Одна из них состоит из разрезанных вдоль оси цилиндрических ДР, расположенных внутри металлической полости и связывающихся через крестообразную [5] или прямоугольную апертуры в металлической диафрагме [6]. Рабочими колебаниями являются два гибридных вырожденных колебания $H E E_{11 \delta}, H E H_{11 \delta}$. Вторая конструкция использует резонаторы сложной формы, образованной из двух соединенных друг с другом прямоугольных диэлектрических колец, напоминающих восьмерку [7]. Рабочими являются два низших $T E_{01 \delta}$ колебания прямоугольных колец, недостатком которых являются повышен- 